\title{
PREDICTORS OF MAJOR BLEEDING AMONG ATRIAL FIBRILLATION PATIENTS ON WARFARIN
}

\author{
LAILA M MATALQAH ${ }^{1 *}$, ALAA YEHYA ${ }^{2}$, GHAITH M AL-TAANI ${ }^{2}$
}

${ }^{1}$ Department of Basic Medical Sciences, Faculty of Medicine, Yarmouk University, Irbid, Jordan. ${ }^{2}$ Department of Pharmacy Practice, Faculty of Pharmacy, Yarmouk University, Irbid, Jordan. Email: laila.m@yu.edu.jo

Received: 27 September 2018, Revised and Accepted: 04 December 2018

ABSTRACT

Objective: Bleeding is the most serious complication associated with anticoagulation therapy. The purpose of this study was to estimate the frequency of major bleeding related to warfarin and to identify its predictors in patients with atrial fibrillation (AF).

Methods: Patients with AF treated with warfarin at Penang General Hospital in Malaysia were identified according to the international classification of disease, Ninth Revision, Clinical Modification (ICD-9). The medical reports of 1611 patients were reviewed, bleeding events were set as primary end point which were identified in 313 patients. Demographic and clinical data were retrieved and warfarin therapy-related parameters including dose, therapy duration, and prothrombin time-international normalized ratio (PT-INR) were recorded and analyzed using descriptive statistics.

Results: Of the 313 patients, 28 patients with major bleeding events were identified. Gastrointestinal bleeding was the major type of bleeding, which accounts for $68 \%(n=17)$ of the cases. The frequency of major bleeding events among all AF patients was $1.7 \%$. High PT-INR value was found in $96.3 \%$ $(n=28)$ of the patients, thereby making it the primary predictor of bleeding events. Other predictors including, advanced age, other comorbidities such as hypertension and multiple anticoagulation therapy were also observed to be significant.

Conclusion: Lower doses of warfarin are recommended to achieve target PT-INR range similar to that reported previously for Asian populations. A regular clinical review for bleeding predictors is essential for maximizing the time spent by the patient taking warfarin in the optimal therapeutic range and for making recommended therapy adjustment.

Keywords: Major bleeding, Warfarin, Atrial fibrillation, Anticoagulants, Malaysian patients.

(C) 2019 The Authors. Published by Innovare Academic Sciences Pvt Ltd. This is an open access article under the CC BY license (http://creativecommons. org/licenses/by/4. 0/) DOI: http://dx.doi.org/10.22159/ajpcr.2019.v12i2.29955

\section{INTRODUCTION}

Atrial fibrillation (AF) is the most common clinically significant arrhythmias and is estimated to be responsible for approximately $15-20 \%$ of all strokes [1]. It counts as the main indication for longterm treatment with warfarin [2]. Anticoagulation therapy with warfarin effectively reduces the risk of ischemic stroke associated with AF; however, it increases the risk for major bleeding. Clinical studies revealed that the risk of intracranial hemorrhage, the most common site of bleeding, is as great as that of thromboembolic events which warfarin is used to prevent $[3,4]$. Therefore, optimal use of warfarin therapy for $\mathrm{AF}$ requires a precise assessment for established risk factors of bleeding such as advanced age, hypertension, stroke, alcoholism, and malignancy [5]. In addition, rigorous reporting of warfarin-associated bleeding is warranted, as patients who bleed often discontinue treatment, which put them at a higher risk of thromboembolism [6,7].

The current dosing guidelines emphasize the importance of adjusting warfarin dose to maintain the patient's prothrombin time-international normalized ratio (PT-INR) 2-3 [8]. European studies reported major bleeding incidence under warfarin therapy for non-valvular AF as 1.6-2.5\% per year with adjusted standard-dose warfarin (PT-INR 2.0-4.5) [9]. In Japan, a study reported an incidence of major bleeding of $6.6 \%$ per year with adjusted standard-dose warfarin (PT-INR 2.2-3.5) and $0 \%$ per year with adjusted low-dose warfarin (PT-INR 1.5-2.1) [10], suggesting that appropriate control by warfarin therapy might differ between populations. In Malaysia, a higher number of stroke cases and lower rates of anticoagulant use were reported compared to other countries in Europe and South Africa [11]. With the increase of longterm warfarin therapy, there is a pressing need to identify clinical features that raise the risk of severe bleeding complications. The purpose of this study was to estimate the frequency of major bleeding associated with the use of warfarin and to identify bleeding risk factors among patients with $\mathrm{AF}$ in Malaysia.

\section{METHODS}

\section{Study design and settings}

A retrospective study was conducted in Penang General Hospital (PGH), a large integrated Healthcare Delivery System located in Penang state in northwest of Malaysia. All patients (18 years and older), who had been diagnosed with $\mathrm{AF}$ and admitted to the hospital with any type of bleeding between January 2005 and December 2011, were identified using the international classification of disease, Ninth Revision, Clinical Modification (ICD-9), as the following, ICD-427.31 (identifies cases with AF) ICD-T45.515 (side effects of anticoagulants), and ICD-459.0 (hemorrhage). In total, there were 313 patients with AF, who presented with bleeding, of 1611 patients with AF. This study was approved by Medical Research Ethics Committee of the Ministry of Health and by the Clinical Research Centre.

\section{Data collection}

Demographic data of 313 patients included in the study (e.g., age, gender, and race) and clinical characteristic of their disease such as site of bleeding (intracranial, gastrointestinal, intraocular, intrarenal, etc.). Other medical comorbidities such as Hypertension, stroke, transient ischemic attack, diabetes mellitus, myocardial infarction, and congestive heart failure; and concomitant drug use, for example, statin and aspirin were obtained from admission medical records. Furthermore, warfarin dose and duration of therapy, INR measurement closest to the onset of symptoms, and other laboratory tests (PT, platelet count, and HGB) were recorded. CHADS2 score (congestive heart failure, hypertension, age $\geq 75$, diabetes mellitus, and prior stroke or transient ischemic attack) was calculated for each patient. 
Definition of major bleeding

It has been established that the definition of major bleeding needs to be based on objective criteria, major bleeding events are those which result in death, considered as life-threatening and cause chronic sequelae or consume major health-care resources. With this in mind, the Subcommittee on Control of Anticoagulation of the Scientific and Standardization Committee of the International Society on Thrombosis and Haemostasis sets the following criteria for major bleeding in nonsurgical patients [12]:

1. Fatal bleeding, and/or

2. Symptomatic bleeding in a critical area or organ, such as intracranial, intraspinal, intraocular, retroperitoneal, intra-articular or pericardial, or intramuscular with compartment syndrome, and/or

3. Bleeding causing a fall in hemoglobin level of $\geq 20 \mathrm{~g} / \mathrm{L}(1.24 \mathrm{mmol} / \mathrm{L})$, or leading to transfusion of two or more units of whole blood or red blood cells.

\section{Statistical analysis}

The Statistical Package for the Social Sciences (IBM SPSS statistics version 20) Microsoft program was used for data analysis. The type, site, and frequency of bleeding events were recorded. Descriptive analysis for demographic data and clinical characteristics of patients enrolled was conducted. For continuous variable, means and standard deviation were used.

\section{RESULTS}

A total of 1611 adults (18 and older), who had been diagnosed with AF and received healthcare in PGH, were identified. Patients $(n=313)$ had adverse effects of bleeding during warfarin therapy were then identified using the ICD code. Systematic revision of the medical files revealed that 28 patients had major bleeding event at time of admission. The frequency of major bleeding events among all $\mathrm{AF}$ patients was $1.7 \%$.

In this study, the majority of cases were Malay, followed by Chinese, which reflects ethnicities distribution in the state of Penang. In terms of gender distribution, two-third of the cases were males $(n=17)$. The mean age at the time of bleeding event was 68.8 years. In addition to AF, patients had other comorbidities, including hypertension was the most frequent $71.4 \%(n=20)$ followed by diabetes mellitus $32.1 \%(n=9)$. Furthermore, all patients were on fibrates, $64 \%$ were on statins and $50 \%$ were on antiplatelet, for example, aspirin or clopidogrel.

The CHADS2 scoring system is a simple system that can be used to assess the annual risk of stroke in AF [13]. The risk for stroke was calculated in this group of patients using CHADS2 score. Treatment with warfarin is recommended for a CHADS2 score of $\geq 2$. Notably 22 patients had a risk of $<2$ of four. Demographic and clinical characteristic are demonstrated in Table 1.

Regarding the site of major bleeding during warfarin therapy, gastrointestinal bleeding (GIB) was most frequently reported, 19 presented with clinical symptoms including of hemoptysis, black stool, and severe gum bleeding. Major bleeding at other sites was reported by 9 patients, distributed as the following: Intraocular $(n=3)$, intramuscular with compartment syndrome $(n=3)$, renal $(n=1)$, intraarticular or pericardial $(n=1)$ and intracranial $(n=1)$ (Table 2$)$.

The mean dose of warfarin was $3.1 \mathrm{mg}$, for the mean of $4.0 \pm 1.2$ years. PT-INR value was calculated for each patient with major bleeding as the mean of all previous tests, including the one at time of admission. Notably, INR values for all patients were above the recommended range (2-3). The completed clinical characteristics of the case are presented in Table 2.

Only one patient had subdural intracranial hemorrhage, a Malay woman 46 years old, with a previous history of prosthetic valve and chronic heart failure, was admitted with severe headache, nausea, and vomiting for more than 4 days. The mean arterial pressure was 135/78 (Table 3).
Table 1: Demographic and clinical characteristic of cases with major bleeding

\begin{tabular}{ll}
\hline Variables & $\mathbf{n}(\mathbf{\%})$ \\
\hline Mean age & 68.8 years \\
Gender & \\
Male & $17(60.7)$ \\
Female & $11(39.3)$ \\
Race & \\
Malay & $10(35.7)$ \\
Chinese & $18(64.3)$ \\
Age groups & \\
<65 & $8(28.6)$ \\
65-79 & $15(53.6)$ \\
>80 & $5(17.8)$ \\
Comorbidities & \\
Hypertension & $20(71.4)$ \\
Diabetes mellitus & $9(32.1)$ \\
Cerebrovascular disease & $7(25.0)$ \\
Coronary artery disease & $4(14.3)$ \\
Congestive heart failure & $3(10.7)$ \\
Prosthetic valve & $3(10.7)$ \\
Hyperlipidemia & $3(10.7)$ \\
Myocardial infarction & $1(3.7)$ \\
CHAD2 score & \\
<2 & $22(78.6)$ \\
3 & $3(10.7)$ \\
Smoking & $3(10.7)$ \\
Yes & \\
Alcohol & $1(3.7)$ \\
Yes & $7(25.1)$ \\
Fedications used & \\
Statins & $11(39.4)$ \\
Beta-blockers & $13(46.4)$ \\
Antiplatelets (aspirin or clopidogrel) \\
Digoxin & $18(0.0)$ \\
ACE inhibitors & $16(57.1)$ \\
Diuretics & $14(50.0)$ \\
Gastroprotective (H2-receptor blocker, PPI) \\
Angiotensium channel blockers \\
\hline
\end{tabular}

Table 2: Sites and frequencies of major bleeding events during warfarin therapy

\begin{tabular}{ll}
\hline Site of bleeding & $\mathbf{n}(\mathbf{\%})$ \\
\hline Gastrointestinal & $19(67.9)$ \\
Intraocular & $3(10.7)$ \\
Intramuscular with compartment syndrome & $3(10.7)$ \\
Renal hemorrhage & $1(3.7)$ \\
Intracranial & $1(3.7)$ \\
Intra-articular or pericardial & $1(3.7)$ \\
INR level (at admission) & \\
$2-3$ & $1(3.7)$ \\
$3.1-4$ & $3(10.7)$ \\
$4.1-6$ & $11(39.3)$ \\
$6-8$ & $7(25.0)$ \\
$>8$ & $6(21.4)$ \\
Platelets & \\
More or equal $50 \times 10^{9}$ cells/L & $15(53.6)$ \\
$\leq 50 \times 10^{9}$ cells $/ \mathrm{L}$ & $13(46.4)$ \\
\hline
\end{tabular}

\section{DISCUSSION}

Long-term treatment with anticoagulation therapy is recommended stroke prophylaxis in patients diagnosed with AF $[14,15]$. However, treatment with warfarin is complicated due to the variability in the biological response to the drug $[16,17]$, narrow therapeutic index, drug-food interactions $[18,19]$, and the risk of thrombotic or bleeding events [6]. 
Table 3: Clinical characteristic of the intracranial hemorrhage case

\begin{tabular}{ll}
\hline Type of intracranial hemorrhage & Subdural \\
\hline Computed tomography done? & Yes \\
Magnetic resonance done? & No \\
Mean arterial pressure & $135 / 78$ \\
Clinical features of intracranial hemorrhage & Hemiparesis \\
Estimated time from onset of symptoms to & $>7$ days \\
presentation & \\
CT scan: Size of hematoma & 0.5 \\
CT scan: Location of hematoma & $\begin{array}{l}\text { Subdural hematoma } \\
\end{array}$ \\
& (cerebral edema) \\
\hline
\end{tabular}

This study aimed at describing the frequency and sites of major bleeding events during warfarin therapy in patients with atrial fibrillation who admitted to PGH in Malaysia. The frequency of major bleeding was 1.7\% which is lower than what was reported earlier as $10-16 \%[20,21]$. GIB was the major site of bleeding which accounts for about $68 \%$ of the cases $(n=17)[22,23]$. This is in agreement with previous reports showing that the rate of GIB was $0-67 \%$. In the present study, other sites of bleeding were presented with lower frequencies: $10.7 \%$ intraocular, $10.7 \%$ intramuscular with compartment syndrome, and only one case with either renal hemorrhage, intracranial, or intraarticular hemorrhage.

Patients getting authorization of refills for their warfarin prescription is a common practice. However, monitoring in fact, a meta-analysis of five major studies for the primary prevention of stroke in AF patients in Western countries reported that thromboembolic events increased when PT-INR was <2.0, whereas hemorrhagic events became increasingly more frequent if PT-INR was $\geq 3.0$ [24]. In this study, the average doses of warfarin used in the cases of major bleeding were $3.1 \mathrm{mg}$; however, $96.3 \%$ of the cases had PT-INR value above 3 during the event of bleeding (recommended range is 2-3), which makes it the primary predictor of bleeding in those cases. This was not surprising because intensity of anticoagulation highly correlates with the risk of bleeding in warfarin patients in most studies $[22,25,26]$. To prevent the thromboembolic event while minimizing the risk of bleeding, an anticoagulation intensity at an INR of 2.0 could be an alternative anticoagulation strategy to traditional range, that is, 2.0-3.0.

It has been established earlier that ethnicity influences warfarin sensitivity. Several studies reported higher incidence of major bleeding among Asian population than in European countries and the US [27-29], suggesting that lower doses are needed to achieve the target PT-INR [30]. This might be due to the variability in the biological response to warfarin or the average body mass index, which is considered small for Asian population [16,17].

It was noteworthy that the age in case of major bleeding was $>65$ years old, with a history of comorbidities, mainly hypertension and diabetes mellitus, the use of aspirin was recorded (INR value $\geq 3$ ) in the majority of the cases. Previous studies showed that age, hypertension, diabetes mellitus, and the use of aspirin independent predictors of stroke associated with $\mathrm{AF}[23,31-35]$.

In this study, the most common cases of major bleeding fall in the age group with the range between 65 and 80 years old. Several mechanisms were proposed to increase the risk of bleeding in elderly patients, slow metabolism rate of warfarin, an elevated risk of drug interactions due to polypharmacy and chronic illnesses [36,37]. Whether older age increases the risk of bleeding in patients treated with warfarin is controversial [22]. However, it is well known that persons older than 80 or 85 years of age do have a significant risk of bleeding [36]. Therefore, warfarin should be cautiously used in elderly patients, especially in extremely old patients. Recent guidelines recommend using lower intensity anticoagulation therapy in patients older than 65 years of age [38]. Concomitant use of proton-pump inhibitors significantly reduces the risk of GIB in patients treated with warfarin [39]. Therefore, acid suppressants may be considered in patients with a history of GIB during warfarin therapy.

The current guidelines recommend that the use of multiple therapy: Warfarin, aspirin, or clopidogrel is acceptable for shortterm treatment (up to 4 weeks) in patients with AF. Discontinuing of nonsteroidal anti-inflammatory drugs (NSAIDs) or adjusting warfarin dose should be considered if INR increases after starting the combination therapy $[15,40]$. A previous study in Malaysia identified peptic ulcer as the most common cause of admitted cases of GIB, and the use of NSAIDs being the major exacerbating factor [41]. Moreover, coadministration of medications with warfarin increases the risk of drug-drug interactions. All admitted patients with major bleeding were on fenofibrate therapy; an oral antilipidemic agent that has reported to response to warfarin by affecting coagulation factors synthesis (II, V, and VII) and inhibition of cytochrome P4503A4 (CYP3A4) inhibitor liver enzyme [42]. Rigorous monitoring of the INR, at least 3 times per week, is recommended in case of concomitant use of warfarin and fenofibrate therapy. Patients are reluctant to undergo regular clinical assessment, and emerging risk factors of bleedings are often underreported several months after the initiation of warfarin therapy.

In Malaysia, warfarin has been the mainstay in patients with $\mathrm{AF}$, who require anticoagulation therapy for the prevention of thrombosis. Anticoagulants use reduces the risk of having a stroke in patients with atrial fibrillation, but associated with various adverse effects, mainly bleeding events $[7,8]$. Monitoring of warfarin dose is mandatory in the first 3 months of therapy, given that major bleeding events occur more frequently during this period. Furthermore, interventions made by clinical pharmacists are successful in identifying and rectifying the different types of drug-related problems in patients with multiple drug use [43]. Community pharmacists may also contribute to the detection of adverse effects attributed to new medications uses and identify incorrect use of medicines [44].

\section{Study limitations}

First, the number of patients was rather small and the observation period was relatively short. Second, since the present study was retrospective, the incidence of bleeding could not be evaluated. Additional cohort large-scale clinical trials are required to develop the optimal control of anticoagulation therapy for the prevention of stroke among AF patients.

\section{CONCLUSION}

INR is the gold standard method of evaluating the risk of bleeding in patients taking warfarin. Lower doses of warfarin are recommended to achieve target PT-INR range similar to that reported for Asian populations. A regular clinical review for bleeding predictors is essential for maximizing the time spent by the patient taking warfarin in the optimal therapeutic range and for making recommended therapy adjustment.

\section{AUTHORS' CONTRIBUTIONS}

LMM has the major contribution in designing and coordinating the study, participated in data collection, statistical analysis and interpretation of data, and drafted the manuscript. KMR conceived the research idea, participated in statistical analysis and interpretation of data, and edited the final version of the manuscript for publication. AY helped in interpretation of data and drafted and edited the final version of the manuscript for publication. GHA helped in statistical analysis and edited and revised the final version of the manuscript for publication.

\section{CONFLICTS OF INTEREST}

The authors declare that there are no conflicts of interest with this work. 


\section{REFERENCES}

1. Xu J, Luc JG, Phan K. Atrial fibrillation: Review of current treatment strategies. J Thorac Dis 2016;8:E886-E900.

2. Katritsis DG, Gersh BJ, Camm AJ. Anticoagulation in atrial fibrillation - current concepts. Arrhythm Electrophysiol Rev 2015;4:100-7

3. Senoo K, Lane D, Lip GY. Stroke and bleeding risk in atrial fibrillation. Korean Circ J 2014;44:281-90.

4. Mittal MK, Rabinstein AA. Anticoagulation-related intracranial hemorrhages. Curr Atheroscler Rep 2012;14:351-9.

5. Hughes M, Lip GY, Guideline Development Group for the NICE national clinical guideline for management of atrial fibrillation in primary and secondary care. Risk factors for anticoagulation-related bleeding complications in patients with atrial fibrillation: A systematic review. QJM 2007:100:599-607.

6. Healey JS, Oldgren J, Ezekowitz M, Zhu J, Pais P, Wang J, et al. Occurrence of death and stroke in patients in 47 countries 1 year after presenting with atrial fibrillation: A cohort study. Lancet 2016;388:1161- 9 .

7. Steinberg BA, Piccini JP. Anticoagulation in atrial fibrillation. BMJ 2014;348:g2116.

8. Kuruvilla M, Gurk-Turner C. A review of warfarin dosing and monitoring. Proc (Bayl Univ Med Cent) 2001;14:305-6

9. Roskell NS, Samuel M, Noack H, Monz BU. Major bleeding in patients with atrial fibrillation receiving Vitamin $\mathrm{K}$ antagonists: A systematic review of randomized and observational studies. Europace 2013;15:787- 97

10. Suzuki S, Yamashita T, Kato T, Fujino T, Sagara K, Sawada H, et al. Incidence of major bleeding complication of warfarin therapy in japanese patients with atrial fibrillation. Circ J 2007;71:761-5.

11. Guo Y, Lip GY, Apostolakis S. The unmet need of stroke prevention in atrial fibrillation in the far east and South East Asia. Malays J Med Sci 2012;19:1-7

12. Schulman S, Kearon C, Subcommittee on Control of Anticoagulation of the Scientific and Standardization Committee of the International Society on Thrombosis and Haemostasis. Definition of major bleeding in clinical investigations of antihemostatic medicinal products in nonsurgical patients. J Thromb Haemost 2005;3:692-4.

13. Chen JY, Zhang AD, Lu HY, Guo J, Wang FF, LiZC, et al. CHADS2 versus CHA2DS2-VASc score in assessing the stroke and thromboembolism risk stratification in patients with atrial fibrillation: A systematic review and meta-analysis. J Geriatr Cardiol 2013;10:258- 66.

14. Mitine C, Leunens G, Verstraete J, Blanckaert N, Van Dam J, Dutreix A, et al. Is it necessary to repeat quality control procedures for head and neck patients? Radiother Oncol 1991;21:201-10.

15. Ezekowitz MD, Bridgers SL, James KE, Carliner NH, Colling CL, Gornick CC, et al. Warfarin in the prevention of stroke associated with nonrheumatic atrial fibrillation. Veterans affairs stroke prevention in nonrheumatic atrial fibrillation investigators. N Engl J Med 1992:327:1406-12

16. Barcellona D, Contu P, Marongiu F. Patient education and oral anticoagulant therapy. Haematologica 2002;87:1081-6.

17. Taylor FC, Ramsay ME, Tan G, Gabbay J, Cohen H. Evaluation of patients' knowledge about anticoagulant treatment. Qual Health Care 1994;3:79-85.

18. Greenblatt DJ, von Moltke LL. Interaction of warfarin with drugs, natural substances, and foods. J Clin Pharmacol 2005;45:127-32.

19. Holbrook AM, Pereira JA, Labiris R, McDonald H, Douketis JD, Crowther M, et al. Systematic overview of warfarin and its drug and food interactions. Arch Intern Med 2005; 165:1095-106.

20. Levine MN, Raskob G, Landefeld S, Kearon C. Hemorrhagic complications of anticoagulant treatment. Chest 2001;119:108S-121S

21. Michael S, Sobel MS. Anticoagulants: To bleed or not to bleed, that is the question. Semin Vasc Surg 2002;15:256-67.

22. Landefeld CS, Beyth RJ. Anticoagulant-related bleeding: Clinical epidemiology, prediction, and prevention. Am J Med 1993;95:315-28.

23. Beyth RJ, Quinn LM, Landefeld CS. Prospective evaluation of an index for predicting the risk of major bleeding in outpatients treated with warfarin. Am J Med 1998;105:91-9.

24. McBride R. Risk factors for stroke and efficacy of antithrombotic therapy in atrial fibrillation. Analysis of pooled data from five randomized controlled trials. Arch Intern Med 1994;154:1449-57.

25. Choudari CP, Palmer KR. Acute gastrointestinal haemorrhage in patients treated with anticoagulant drugs. Gut 1995;36:483-4.

26. Gage BF, Yan Y, Milligan PE, Waterman AD, Culverhouse R, Rich MW, et al. Clinical classification schemes for predicting hemorrhage: Results from the national registry of atrial fibrillation (NRAF). Am Heart $\mathbf{J}$ 2006;151:713-9.

27. Hylek EM, Held C, Alexander JH, Lopes RD, De Caterina R, Wojdyla DM, et al. Major bleeding in patients with atrial fibrillation receiving apixaban or warfarin: The ARISTOTLE trial (Apixaban for reduction in stroke and other thromboembolic events in atrial fibrillation): Predictors, characteristics, and clinical outcomes. J Am Coll Cardiol 2014;63:2141-7.

28. Blin P, Dureau-Pournin C, Lassalle R, Abouelfath A, Droz-Perroteau C, Moore $\mathrm{N}$, et al. A population database study of outcomes associated with Vitamin K antagonists in atrial fibrillation before DOAC. Br J Clin Pharmacol 2016;81:569-78.

29. Hollowell J, Ruigómez A, Johansson S, Wallander MA, GarcíaRodríguez LA. The incidence of bleeding complications associated with warfarin treatment in general practice in the United Kingdom. Br J Gen Pract 2003;53:312-4.

30. Lewison G, Kumar S, Wong CY, Roe P, Webber R. The contribution of ethnic groups to Malaysian scientific output, 1982-2014, and the effects of the new economic policy. Scientometrics 2016;109:1877-93.

31. Fang MC, Go AS, Hylek EM, Chang Y, Henault LE, Jensvold NG, et al. Age and the risk of warfarin-associated hemorrhage: The anticoagulation and risk factors in atrial fibrillation study. J Am Geriatr Soc 2006;54:1231-6.

32. Torn M, Bollen WL, van der Meer FJ, van der Wall EE, Rosendaal FR. Risks of oral anticoagulant therapy with increasing age. Arch Intern Med 2005; $165: 1527-32$

33. Kuijer PM, Hutten BA, Prins MH, Büller HR. Prediction of the risk of bleeding during anticoagulant treatment for venous thromboembolism. Arch Intern Med 1999:159:457-60.

34. Kearon C, Ginsberg JS, Kovacs MJ, Anderson DR, Wells P, Julian JA, et al. Comparison of low-intensity warfarin therapy with conventionalintensity warfarin therapy for long-term prevention of recurrent venous thromboembolism. N Engl J Med 2003;349:631-9.

35. Laupacis A, Boysen G, Connolly S, Ezekowitz M. Warfarin versus aspirin for prevention of thromboembolism in atrial fibrillation: Stroke prevention in atrial fibrillation II study. Lancet 1994;343:687-91.

36. Fihn SD, Callahan CM, Martin DC, McDonell MB, Henikoff JG, White RH, et al. The risk for and severity of bleeding complications in elderly patients treated with warfarin. The national consortium of anticoagulation clinics. Ann Intern Med 1996;124:970-9.

37. Fitzmaurice DA, Blann AD, Lip GY. Bleeding risks of antithrombotic therapy. BMJ 2002;325:828-31.

38. Wann LS, Curtis AB, January CT, Ellenbogen KA, Lowe JE, Estes NA $3^{\text {rd }}$, et al $2011 \mathrm{ACCF} / \mathrm{AHA} / \mathrm{HRS}$ focused update on the management of patients with atrial fibrillation (updating the 2006 guideline): A report of the american college of cardiology foundation/American heart association task force on practice guidelines. Circulation 2011:123:104- 23

39. Lin KJ, Hernández-Díaz S, García Rodríguez LA. Acid suppressants reduce risk of gastrointestinal bleeding in patients on antithrombotic or anti-inflammatory therapy. Gastroenterology 2011;141:71-9.

40. Camm AJ, Kirchhof P, Lip GY, Schotten U, Savelieva I, Ernst S, et al. Guidelines for the management of atrial fibrillation: The task force for the management of atrial fibrillation of the European society of cardiology (ESC). Europace 2010;12:1360-420.

41. Mallick KK. Common causes of gastrointestinal bleeding diagnosed by endoscopy/colonoscopy at hospital Sultanah Bahiyah, Alor Setar, Malaysia. IIOSR J Dent Med Sci 2014;13:36-41.

42. Teklay G, Shiferaw N, Legesse B, Bekele ML. Drug-drug interactions and risk of bleeding among inpatients on warfarin therapy: A prospective observational study. Thromb J 2014;12:20.

43. George RM, James E, Vijayalakshmi S. Clinical pharmacist's interventions on drug related problems in a tertiary care hospital. Int J Pharm Pharm Sci 2015;7:401-4.

44. Cheema E, Singer DR. Community pharmacist-led new medicine service for patients with a long term medical condition: A crosssectional study. Int J Pharm Pharm Sci 2017;9:129-33. 